\title{
ELADIO DIESTE Y LA CERÁMICA ESTRUCTURAL EN URUGUAY
}

\section{(ELADIO DIESTE AND STRUCTURAL BRICK IN URUGUAY)}

\author{
Antonio J. Mas Guindal \\ Profesor Titular, Dr. Arquitecto. Universidad Politécnica de Madrid. Dpto. Estructuras de la Edificación. Escuela Técnica Superior \\ de Arquitectura (ETSAM)
}

Josep Ma Adell

Profesor Titular, Doctor Arquitecto. Universidad Politécnica Madrid (UPM). Dpto. Construcción y Tecnología Arquitectónicas (DCTA). Escuela Técnica Superior de Arquitectura (ETSAM). Director Línea Investigación sobre fábricas en el Grupo de Investigación de Tecnologías Innovadoras y Sostenibles en Edificación (TISE-fábricas)

Fecha de recepción: 2-I-05

ESPAÑA

$109-24$

\section{RESUMEN}

La personalidad de Eladio Dieste queda reflejada en la honradez de su obra arquitectónica e ingenieril, creada con la conciencia de la "economía cósmica", ideada a partir del empleo del ladrillo como material de construcción económico, que gracias a su ingenio e innovaciones revolucionarias, ha conseguido armar y construir en el espacio, con las formas emanadas de emplear la mínima energía constructiva.

Los autores del artículo tuvieron el privilegio de conocer ampliamente a este singular genio, en relación a sus propias actividades profesionales, ilustrándonos ahora sobre la esencia de "la cerámica estructural" de Eladio Dieste, apoyándose en su pensamiento publicado, y centrándose en un par de edificios singulares (la Iglesia de Atlántida y la Iglesia de Durazno), donde reside la esencia de la obra de este Ingeniero, que con el material más antiguo de construcción, ha sabido levantar los espacios más económicos y expresivos que puedan imaginarse.

Las paredes y cubiertas de delgadas superficies regladas y plegadas de Dieste, son de tal esbeltez, que nunca antes se habian podido conseguir con materiales tradicionales, lo que logra con su ingenio y destreza constructiva, contrastando enormemente con la arquitectura de sus contemporáneos (Le Corbusier y Candela, entre otros), hecha con hormigón armado. Las edificaciones de Dieste pueden considerarse como un manifiesto adelantado de la Arquitectura Sostenible, por su eficacia en el empleo de la materia.

\section{SUMMARY}

Eladio Dieste's personality is reflected in the honesty of his architecture and engineering, created in keeping with his "cosmic economy", a conceit consisting essentially in the use of brick as an inexpensive construction material. Applying ingenious reinforcement techniques and revolutionary innovations, he conquered space with forms designed to deploy the least possible energy in building.

The authors of this article had the privilege of knowing this unique genius during their own careers. For the present study, they gleaned the essence of Dieste's "structural brickwork" from his published works, focusing on two singular buildings (the oldest church in Atlántida and Durazno Church) illustrative of the engineer's key concern in his oeuvre: to build the most economic and expressive spaces imaginable with civilization's oldest construction material

The walls and roofs of Dieste's ruled and fluted thin surfaces are more slender than any built ever before with traditional materials. This he achieved with ingenuity and construction skill, using techniques that contrasted starkly with the reinforced concrete approach preferred by his contemporaries (Le Corbusier and Candela, to name but two). For his efficient use of materials, Dieste can be justly viewed as a forerunner of Sustainable Architecture.

\section{SOBRE LA PERSONALIDAD DE ELADIO DIESTE}

A) "No podemos seguir dando por sentado que el arte, la ciencia y la técnica nos han de venir de fuera. Hasta el gran Unamuno llegó a decir: "iQue inventen ellos!», aunque estoy seguro que ésa fue una afirmación polémica que estaría dispuesto a rectificar. Yo le hubiese contestado: «Perdone usted, Don Miguel, pero si inventan ellos mandan ellos». No es moralmente lícito hurtarnos a la vida en ningún campo" (E. Dieste). 


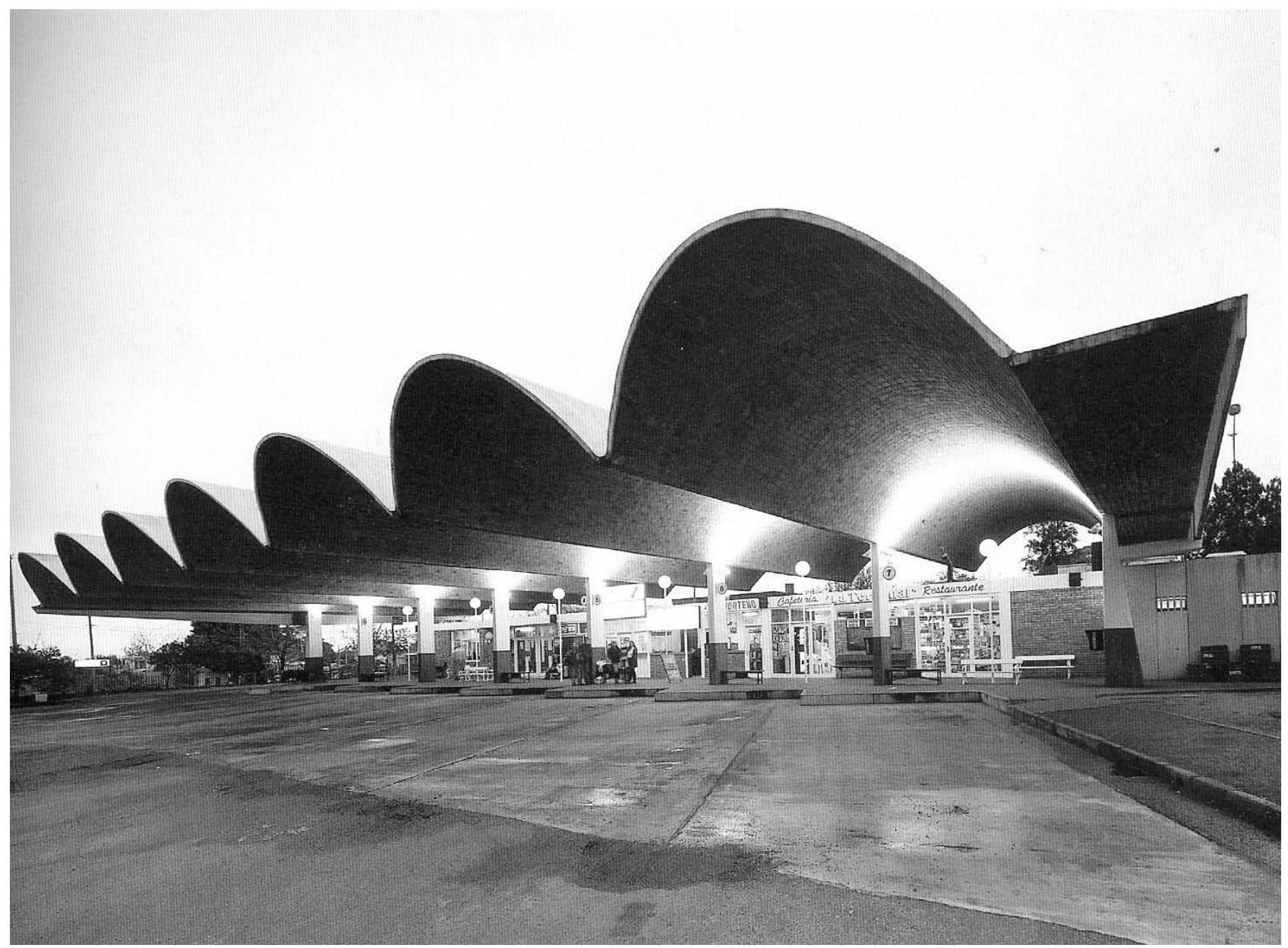

Figura1.- Bóvedas Autoportantes en la Terminal de ómnibus en Salto (Uruguay).

B) “No veo «modelos» por imitar; veo algo mucho más incitante: un camino y sé que tengo brújula” (E. Dieste).

C) "Lo constructivo será siempre imprescindible en la Arquitectura; es como sus huesos y su carne" (E. Dieste).

D) "Importa mucho la coherencia entre lo que nos muestra la forma y la realidad construida; la coherencia nos la vuelve inteligible" (E. Dieste).

E) "La arquitectura que resulta de la aplicación de la fábrica armada ... es como la flor de la construcción misma ... no puede haber Arquitectura sin Construcción” (E. Dieste)

F) “La arquitectura así entendida es poesía; se dice que no todos somos capaces de hacerla, pero todos la necesitan” (E. Dieste).

G) "He procurado ser coherente con las exigencias de mi trabajo. Hacerlo bien. Ello me ha llevado a un camino de descubrimiento, primero de mí mismo. Ese camino usa la forma y ésta debe estar imbricada en las leyes que rigen la materia en equilibrio" (E. Dieste).

Estos textos escogidos entre los múltiples de Eladio Dieste [“A)...G)"], nos definen la personalidad y originalidad del pensamiento y de la obra de este Ingeniero uruguayo.

La abundante y original obra de Eladio Dieste a lo largo de su dilatada vida profesional, no deja dudas de que ha encontrado un camino original, experimentándolo hasta sus últimas consecuencias por su cuenta, ignorando voluntariamente y con conocimiento de causa, el dispendio económico que él apreciaba en la Arquitectura moderna, lo que para él no podía justificarse o "sostenerse", económicamente hablando, en los países subdesarrollados del Sur, donde había que ajustar al máximo, el consumo del cemento por su elevado coste, aunque por el contrario, se podía aprovechar la económica mano de obra (Fig. 1). 


\section{EL DESCUBRIMIENTO DEL VALOR DE LA OBRA DE DIESTE}

Marina Waismann fue uno de los primeros Arquitectos que publicó artículos sobre la originalidad de la obra de Dieste.

El "Arquitecto del Sur", Eladio Dieste, fue descubierto internacionalmente por la "Arquitectura del Norte", a partir de los escritos de Karl Ludwig Diehl publicados en el $9^{\mathrm{TH}}$ IBMAC (International Brick/Block Masonry Conference, Berlín 1991), dejando absolutamente anonadados a los ingenieros alemanes, que no podían creer en la evolución de un material tan antiguo, que ya habían abandonado frente a las nuevas posibilidades que el acero incorporaba en el hormigón armado.

Después de su descubrimiento y por iniciativa del Arquitecto Carlos Clemente, a través de la Universidad y el Obispado de Alcalá de Henares, Eladio Dieste fue invitado a dar a conocer su obra en España e incluso a reproducir algunas de sus edificaciones en la Comunidad de Madrid como la Iglesia de la Atlántida en Alcalá de Henares (aunque de menor tamaño) o la Iglesia de Durazno en Mejorada del Campo, además de diversos tipos de cáscaras.

Los dos autores de este artículo tuvieron la suerte de conocer y tratar a Eladio Dieste, siempre de maestro a humildes alumnos, considerándolo como una de esas cabezas que obtienen su máximo brillo con el paso del tiempo. Dieste, igual que un círculo muy reducido de arquitectos, ingenieros y científicos, donde estarían, Gaudí, Guastavino, Félix Candela, Luis Moya..., ha elevado a las alturas el concepto de edificio de ladrillo.

El ladrillo podría considerarse el material prefabricado más antiguo de la humanidad. Cuando masivamente el mundo romano, lo aprendió de la arquitectura oriental y realizó las bóvedas de crucería de la Basílica de Magencio en Roma, hoy en ruinas, con el record mundial de $25 \mathrm{~m}$ de luz, se pensó que con la cerámica no podría realizarse una estructura de mayores dimensiones. Tuvo que ser Filipo Brunelleschi, quien, dirigiendo personalmente las obras, nos dejó en Santa María dei Fiore, una de las bóvedas de mayor dimensión del mundo y quizá el edificio más bello de toda la Toscana. Parece que toda la construcción de ladrillo, basada en formas funiculares, había llegado a su cenit en lo referente a usar el ladrillo como lo que es, es decir, como elemento comprimido.

Gaudí, siguió usando del ladrillo, como de los materiales frágiles de trabajo a compresión en todas sus obras, basándose en el sencillo esquema de los polígonos funiculares. Así, las bóvedas de la Sagrada Familia o Santa Coloma de Cervelló, fueron resueltas a partir de esquemas funiculares sencillos en donde el valor exacto de la tensión no era determinante y sí lo era, la forma de equili- brio global, entendida esta como el resultado de un equilibrio de empujes y contrarrestos funiculares cuidadosamente diseñados.

Rafael Guastavino y Moreno, desarrolló con innegable éxito en Estados Unidos, desde 188,1 la técnica constructiva cerámica mediterránea. Su defensa a ultranza de las bóvedas cerámicas le hace encontrar grandes ventajas frente a los arcos de piedra, basándose en la resistencia a tracción de las primeras.

Luis Moya trabajo como nadie con la tipología de las bóvedas de trabajo a compresión, cúpulas de revolución, bóvedas poligonales, medio punto, elípticas, nervadas, tratándolas como láminas, aprovechando la facilidad constructiva, que se desprende de la cualidad que da el yeso como elemento de unión cohesiva.

Félix Candela, desarrolló en Méjico toda su investigación acerca del uso de las láminas de hormigón armado, basándose en las posibilidades que la mano de obra barata de aquel país le brindó.

La figura de Eladio Dieste emerge como el último de los grandes gigantes de las bóvedas en el pasado siglo. Su aportación desde la óptica del ingeniero al uso del ladrillo es única, sin antecedentes. Realiza bóvedas de grandes luces basándose en el recurso del pretensado, que muy pocos habían utilizado antes, para corregir el pequeño gran defecto de la fisuración. Los anteriores constructores citados, usaron de la cerámica como elemento siempre comprimido, ayudado por tirantes y zunchos o no. Dieste da un salto cualitativo importante en la medida de prescindir del problema de la fisuración al pretensar. La cerámica postensada, después de un aquilatado estudio analítico puede usarse en grandes dimensiones, ya que las tensiones a las que llega no son grandes y el acero envainado por las isóbaras de tracción en la lámina resuelve el tradicional problema de las tracciones no deseadas.

Su obra, lamentablemente no muy conocida en España hasta hace poco, hace siempre gala de una extremada delicadeza en el diseño de las formas a la vez que de una brillante economía de medios y resultado.

El método de análisis que el mismo nos describe en sus realizaciones es simple, en primer lugar supone un arco cuya directriz sea funicular del peso propio y de las cargas fijas, de sección constante o variable. Así establecido, la aparición de flexiones se deberá a otras cargas distintas de las fijas, que producirán momentos y esfuerzos cortantes. Estas flexiones pueden ser debidas a viento, nieve o cargas puntuales en la cubierta. La realidad final es un escenario de bóvedas cerámicas de doble curvatura inteligentemente diseñadas con la rigidez justa y suficiente para ofrecer soluciones competentes con las soluciones en acero laminado y con una plástica nueva. 


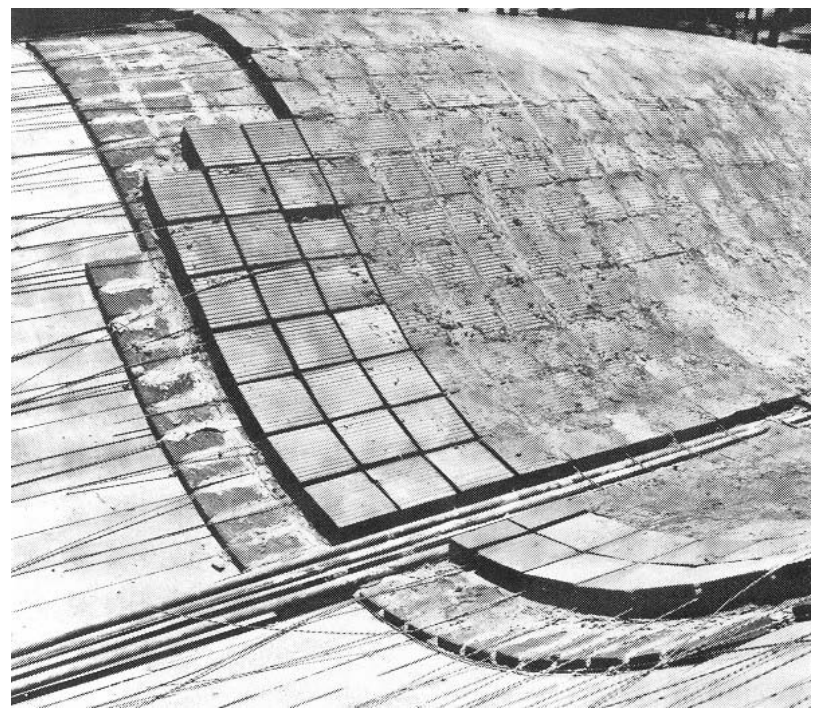

Figura 2.- Construcción de la cubierta ondulada de la Iglesia de la Atlántida con las piezas en retícula y el armado homogéneo, dejando un espacio para incorporar el armado del tirante.

En la Revista Informes de la Construcción no 421 del I.E. Torroja (1992), con el título "Las Bóvedas de la Atlántida", se hablaba de la Iglesia de la Atlántida de Dieste en Uruguay (Montevideo, 1952), y se contrastaba con las Escuelas de la Sagrada Familia de Gaudí (Barcelona, 1909).

Eladio Dieste no fue conocedor de esta obra de Gaudí, cuando hizo la Iglesia de la Atlántida, ya que la obra del Arquitecto catalán, no era entonces conocida, pues Gaudí fue dado a conocer internacionalmente a partir de una publicación del Arquitecto Sert en 1960.

Eladio Dieste, con sus originales y experimentadas teorías, colaboró en el proyecto de reconstrucción de J.M. Adell, que planteaba sobre la cubierta de las Escuelas de la Sagrada Familia de Gaudí a partir de 1992 y cuyo resultado final se publica ahora en este Monográfico con el título "Gaudí y las Bóvedas de las Escuelas de la Sagrada Familia".

\section{LA TÉCNICA CONSTRUCTIVA DE LA CERÁMICA ESTRUCTURAL}

Las singulares obras de Dieste sólo pueden entenderse a partir de los saltos técnicos que realiza en la obra de fábrica, y que para poderlos adumir, hay que ser capaz de dejar de lado los conocimientos previos adquiridos sobre la construcción tradicional de las fábricas y sus materiales.

La "trabazón" ha sido indispensable entre las piezas de toda obra de fábrica, para lograr su estabilidad, lo que se obtiene contrapeando las piezas de sucesivas hiladas entre sí, evitando en todo momento dejar en continuidad llagas verticales.
El "aparejo" se constituyó como una determinada manera fiable, segura y constante, de lograr la "trabazón" entre sus piezas, generándose con ello un patrón constructivo característico de "cada tipo de aparejo y lugar" (aparejo inglés en cruz, aparejo belga, aparejo a tizón a la española, etc.).

La concienzuda colocación tradicional de los ladrillos trabándolos entre sí, manteniendo un determinado aparejo en la obra de fábrica, desaparece totalmente en la arquitectura de Dieste, ya que de forma reflexiva, éste añade a la misma un nuevo componente, "el acero", en barras o alambres, que incorpora de forma regular y homogénea en el conjunto de la fábrica.

Para ello, Dieste dispone en todas sus obras, cuando le conviene, las piezas sin contrapear ni aparejar, lo que genera una retícula bidireccional entre las piezas, donde poder ubicar los alambres o barras de acero, entretejiendo la fábrica en todo su conjunto con un material dúctil, en vez de trabar sus piezas (ver Fig.19.a y b).

Todo ello le permite a Dieste crear la que él denomina "cerámica estructural", donde varía la proporción de armado en función de la ductilidad conjunta que desee generar en la fábrica o de las necesidades tensionales locales que se requieran para los atirantados o postensados, según cual sea la tipología estructural que esté construyendo (Fig.2).

Es interesante resaltar las reflexiones de Eladio Dieste a la hora de elegir el ladrillo (ver portada):

1. Su elevada resistencia mecánica. Pocos saben que en los países industrializados la gran masa del material producido tiene resistencias entre $500 \mathrm{y}$ $1.000 \mathrm{~kg} / \mathrm{cm}^{2}$ y hay ladrillos de precio accesible que alcanzan $1.500 \mathrm{~kg} / \mathrm{cm}^{2}$, resistencias que igualan o superan a las de los mejores hormigones. En Uruguay, Argentina, Brasil, etc., hay también ladrillos de alta calidad.

2. Con la tierra cocida son posibles mampuestos de una liviandad inalcanzable con hormigón o cemento. Y esa liviandad se mantiene al ensamblarlos para construir piezas de dimensiones comparables a las usuales con hormigón armado o ferrocemento.

3. A igualdad de resistencia, el ladrillo tiene un módulo de elasticidad menor que el hormigón, lo que es una ventaja y no un inconveniente, porque da a la estructura una mayor adaptabilidad a las deformaciones. El riesgo de pandeo, si existiera, pueda obviarse usando soluciones como las que empleamos en las cáscaras gausas, que incrementan muy poco el peso y el costo. 
4. Buen envejecimiento: con un mínimo de cuidado la estructura envejece mejor que las de hormigón y resiste también mejor los cambios bruscos de temperatura.

5. Contra lo que puede suponerse, las reparaciones, cambios o agregados, se notan menos que en una estructura de hormigón no revocada.

6. Buen aislamiento térmica de la masa de tierra cocida, incrementada todavía más por la posibilidad de introducirle huecos, ya sean los conocidos por todos en las piezas fabricadas por extrusión o prensado, o los que podrían lograrse incluyendo en su masa granos de cerámica expandida.

7. Mejor comportamiento acústico por el menor $\mathrm{E}^{*}$ y por la facilidad con que se hacen en ladrillo formas acústicamente convenientes.

8. Capacidad de regulación "natural" de la humedad ambiente, de efecto mayor de lo que podría suponerse.

9. La superficie, frente a una de hormigón (y usando deliberadamente una manera no técnica de expresarse) irradia menos calor en verano y nos toma del nuestro en invierno.

10. Con las actuales técnicas de fabricación y con una racionalización global de la industria, se puede obtener un precio por metro cúbico de material fabricado no comparable al de ningún otro de calidad semejante.

11. En muchos casos de que son ejemplo las obras aquí reseñadas, también el costo de la estructura es muy bajo, no fácilmente alcanzable con otros materiales de calidad equivalente. Es legítimo hablar del material porque los procesos constructivos y las formas estructurales a que luego nos referimos lo suponen en mayor o menor medida.

La ventaja de la "cerámica estructural" frente al hormigón armado, está en que al existir muy poco mortero de relleno en la retícula de las juntas entre los ladrillos, se disminuye mucho el tiempo del "tirado", pudiendo desencofrar en sólo 14 horas (no días, como erróneamente se pudiera pensar), agilizándose con ello enormemente la velocidad de ejecución de las obras, e incidiendo muy positivamente en la economía global de la edificación, incluso cuando se emplee mucha mano de obra en la albañilería, aunque sin cualificar.

Con la ventaja de no tener que emplear el aparejo en estas obras, donde el armado está dispuesto en retícula gene-

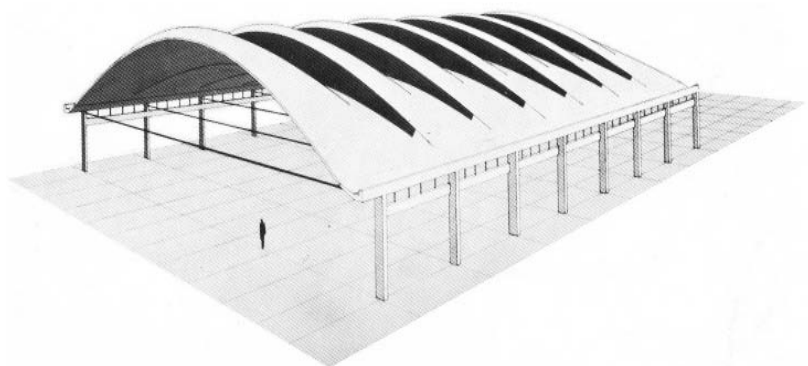

Figura 3.- Vista del conjunto de una nave con Bóvedas Gausas atirantadas.

rando la trabazón entre las piezas de ladrillo, ofreciéndoles ductilidad, se añade la posibilidad de poder generar superficies regladas debidamente armadas bidireccionalmente, siguiendo las ondulaciones propias de las curvaturas de este tipo de superficies, y con mucha mayor ligereza que si fueran macizas de hormigón.

En consecuencia, los encofrados empleados en la obra de Dieste, son mucho más ligeros que los requeridos para el hormigón armado, y además ofrecen una reutilización mucho más rápida y económica.

Lo desarrollado por Dieste (que se aprecia en este Volumen II: Bóvedas), contrasta con la tecnología del Sistema de Albañilería Integral (que se expone en el Volumen I: Muros), donde se logra armar la fábrica en las 3 direcciones del espacio, sin interrumpir por ello el aparejo de la misma, gracias a recurrir al invento de diseñar la pieza cerámica universal, capaz de aumentar sus perforaciones en obra, para poder ubicar el armado vertical de la fábrica a través de los grandes huecos que se abren en las piezas y en la propia obra, y por acceso lateral al nivel que está el albañil.

Respecto al armado, conviene recordar que el mortero no protege suficientemente de la corrosión al acero, y se hace imprescindible emplear armaduras galvanizadas en fábricas vistas, tal y como lo exige la normativa europea EC-6 y española SE-F.

\section{LAS BÓVEDAS GAUSAS DE DIESTE}

Dieste es el inventor de las que denomina "Bóvedas Gausas", cuyas formas geométricas, características estructurales y técnica constructiva, expone ampliamente en sus publicaciones, y cuya economía de materiales responde al hecho de crear la forma siguiendo la directriz del peso propio [Véanse algunos ejemplos: Figs. 3 a 7].

Las características principales de las Bóvedas Gausas se pueden resumir en los siguientes puntos (Dieste):

1. El complejo ladrillo-mortero-hierro se comporta como una unidad estructuralmente viable. Éste 


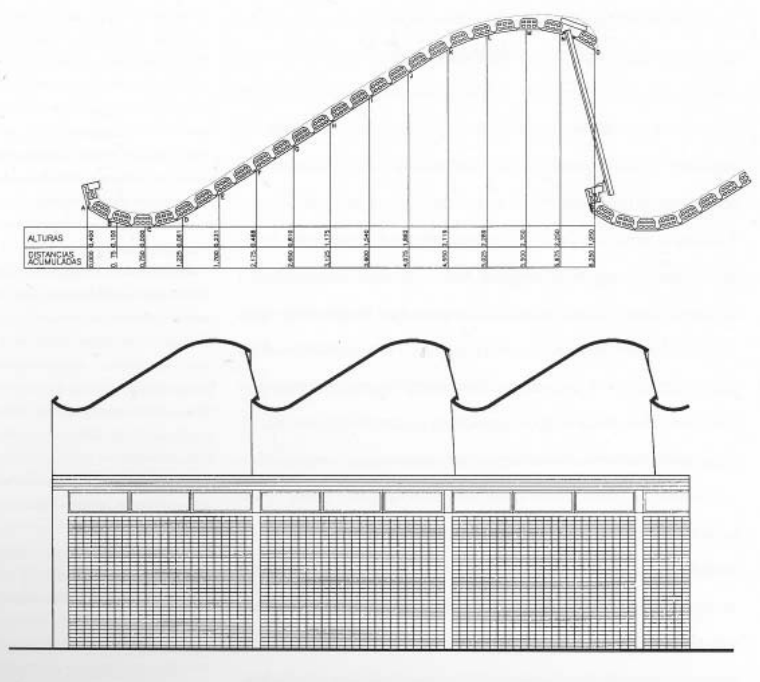

Figura 4.- Detalle de la sección constructiva de una Bóveda Gausa entre lucernarios.

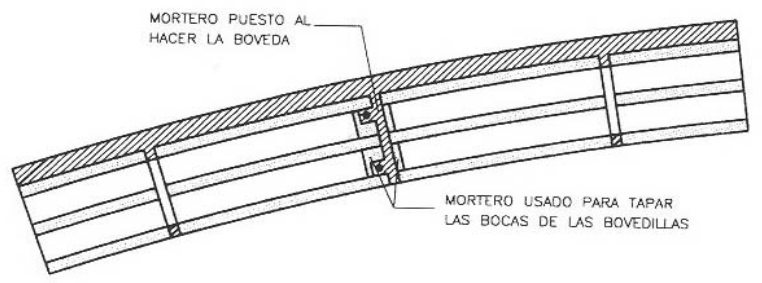

Figura 5.- Sección de la ubicación del armado y el mortero entre las piezas cerámicas.

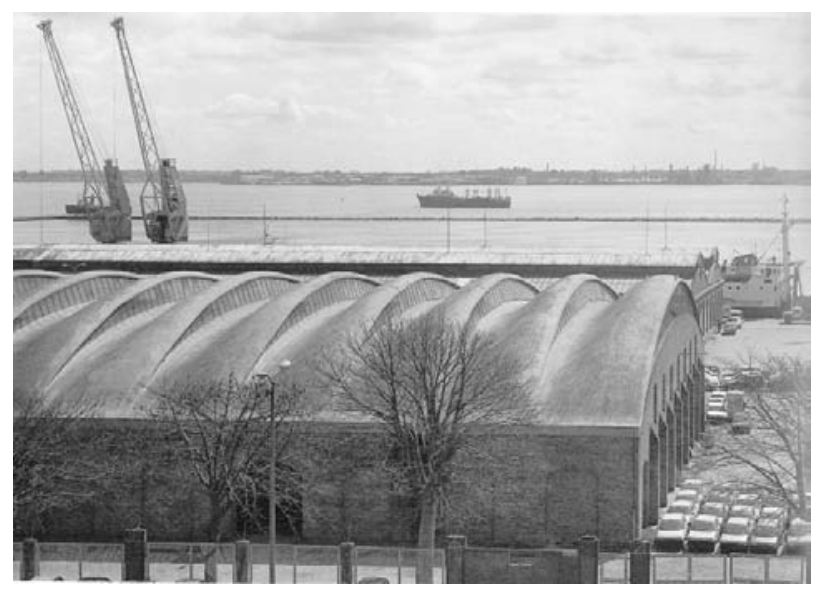

Figura 6.- Vista exterior de las cubiertas Gausas en Montevideo.

fue el hecho básico a partir del que se podía empezar a pensar e intuir.

2. Elegimos como directriz la catenaria, luego el peso produce compresión simple; y esta compresión hace capaz a la estructura de resistir flexiones. Esta capacidad aumenta mucho si consideramos un "mínimo constructivo" de armadura.
3. Las tensiones de compresión debidas al peso propio son independientes de la sección, ya que la fuerza directa es proporcional al peso por unidad de desarrollo, o sea, a la sección. Estas tensiones son bajas: en una bóveda de $100 \mathrm{~m}$ de luz y $10 \mathrm{~m}$ de flecha de compresión es de $27 \mathrm{~kg} / \mathrm{cm}^{2}$ suponiendo un peso específico medio de 2 toneladas/ $\mathrm{m}^{3}$.

4. La armadura mínima asegura que una importante longitud de la cáscara (ampliamente suficiente para asegurar tensiones admisibles con hipótesis sencillas de cálculo) reacciona como una unidad elástica frente a las cargas concentradas.

5. Teniendo en cuenta que el único material a endurecer es el de las juntas y que el "tirado" de la mezcla hace que el mortero tome rápidamente una resistencia que, aun siendo pequeña, puede ser suficiente, se intuye en seguida que, para descimbrar la bóveda, no es necesario esperar el endurecimiento normal del mortero. Esto fue confirmado por los ensayos, no sólo para pequeñas bóvedas, sino para grandes estructuras.

Inmediatamente después de lleno el molde disponemos de una lámina de doble curvatura con las siguientes características (Dieste):

1. Mediante la ondulación que ya describimos hemos podido darle rigidez a voluntad.

2. Las partes no fraguadas, que son las juntas, representan un porcentaje muy pequeño de la superficie total, del orden del $2 \%$.

3. En las juntas, entre las piezas hay una malla de acero que constituye una verdadera red cuyos elementos longitudinales están, a través del mortero, en contacto con las caras de las dovelas que trabajarán a compresión.

Resumiendo, las ideas básicas que informan esta solución son las siguientes (Dieste):

1. Dar forma de catenaria a todas las secciones transversales de la bóveda, de manera que para el peso propio todas las secciones resulten solamente comprimidas.

2. Utilización de la ondulación, con pequeño aumento del peso por $\mathrm{m}^{2}$, para incrementar su momento de inercia y consiguientemente su rigidez al pandeo y su capacidad para resistir acciones que, como el viento, dan curvas de presiones distintas de las del peso propio. 
3. Utilización de piezas prefabricadas de pequeñas dimensiones que se adapten bien a la forma del molde y sean fácilmente manejables. Estas piezas pueden ser de hormigón, normal o poroso, de cerámica o de cualquier otro material El cerámico nos parece el ideal, por lo menos por el momento.

4. Disponer no sólo armadura transversal (según los arcos), cuya función es obvia, sino también longitudinal, de traba, esencial en el funcionamiento del sistema: las diferencias de asentamiento debidas a la diferente flecha provocarían fisuras transversales que harían inoperante la ondulación que nos da la rigidez necesaria por el cálculo, si no hubiera hierro que absorbiera las correspondientes tracciones. Esta ondulación es particularmente necesaria en el momento del desencofrado, cuando el módulo de Young promedio de la cáscara es más bajo. Al desencofrar, el mortero está sólo parcialmente endurecido, las juntas longitudinales están comprimidas por la fuerza directa transversal de la lámina, especialmente grande en estos casos por la importancia de las luces transversales en que se usan y que justifican estas bóvedas y por el hecho de que se hacen muy rebajadas. Esta fuerza directa complementa, por frotamiento, la insuficiente adherencia debida al fraguado incompleto; o sea, contribuye a vincular los sucesivos pares de piezas adyacentes a la junta longitudinal armada.

5. El molde móvil, cuya dimensión longitudinal es una pequeña fracción del largo total del local a techar y cuyo costo es alto, se amortiza en un gran número de usos y grava muy poco el costo final de la cubierta.

6. Como resultado de las ideas anteriores, existe la posibilidad de desencofrar estructuras de grandes dimensiones en plazos cortísimos.

7. Como resultado a su vez de los seis ítems anteriores, tenemos la posibilidad de un ritmo continuo de trabajo con un molde de pequeñas dimensiones.

\section{PAREDES DE SUPERFICIES REGLADAS Y LÁMI- NAS PLEGADAS}

\section{- La Iglesia de la Atlántida (Montevideo, 1952)}

La Iglesia de la Atlántida, es un caso particularizado de las Bóvedas Gausas de Dieste, donde los tirantes no son vistos ya que quedan embebidos en la propia ondulación de la cubierta (Fig. 2).

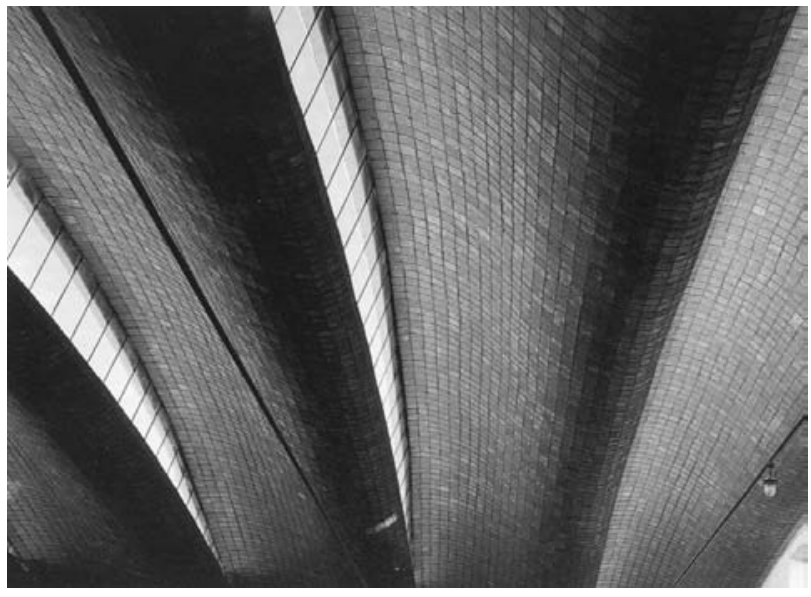

Figura 7.- Vista interior de la luminosidad de la nave cubierta con Bóvedas Gausas.
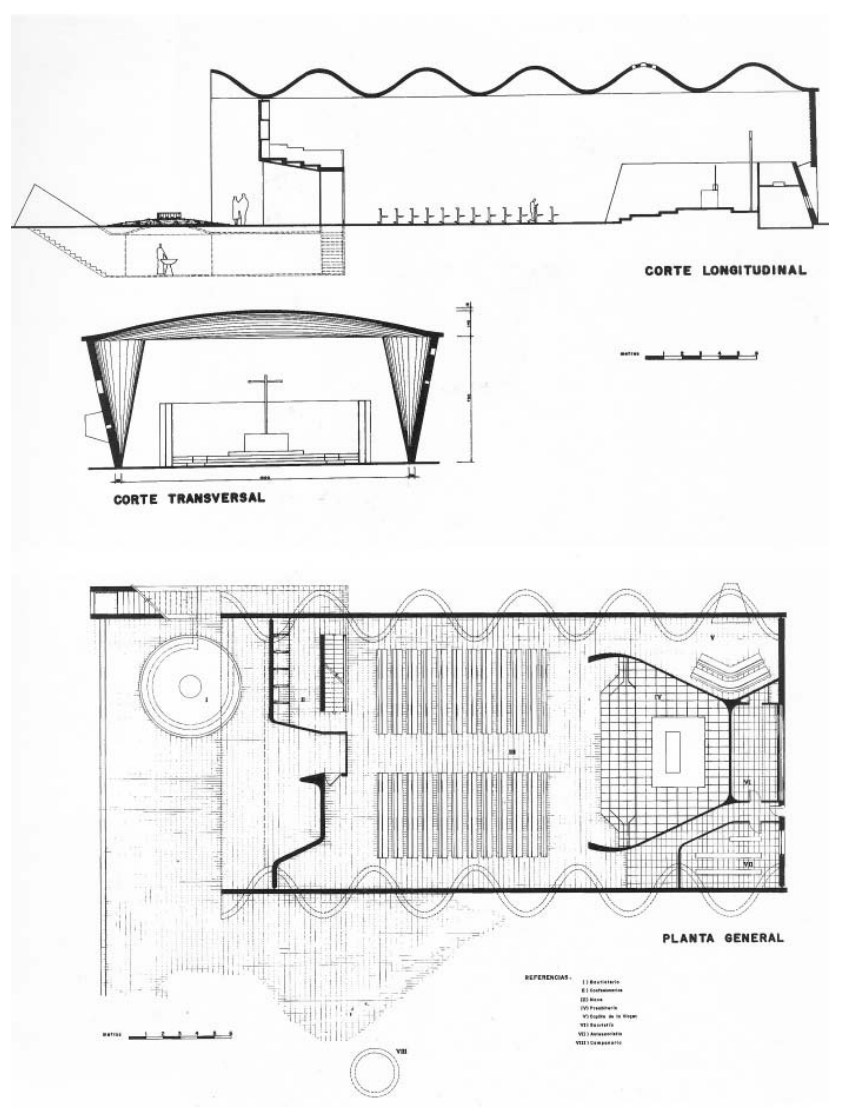

Figura 8.- Planta y secciones de la Iglesia de la Atlántida.

La Iglesia de la Atlántida es de recinto rectangular en su base, pero sus paredes se elevan onduladamente hasta rematarse en una cornisa serpenteante (Fig. 8). El grueso de estos muros es de 2' y $1 / 4$, lo que permite hacer 2 hojas de fábrica vista, con una cámara central de mortero armado de unos 6cm de grueso (Fig. 9) (Fig. 10).

La ondulación de la cubierta, diseñada como sucesivas Bóvedas Gausas unidas entre sí, arranca del plano hori- 


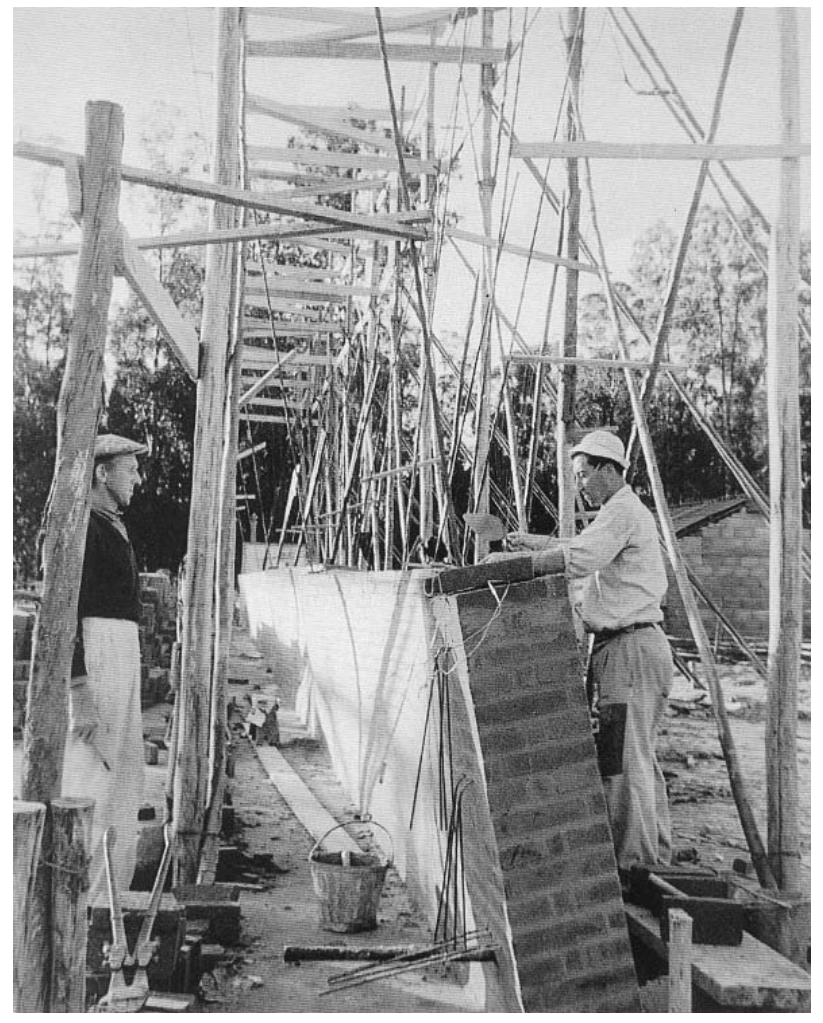

Figura 9.- Arranque de la construcción del muro ondulado de la Iglesia de la Atlántida con 2 hojas de 1'y 1/4 de grueso con un armado en el hueco central de $1 / 4$.

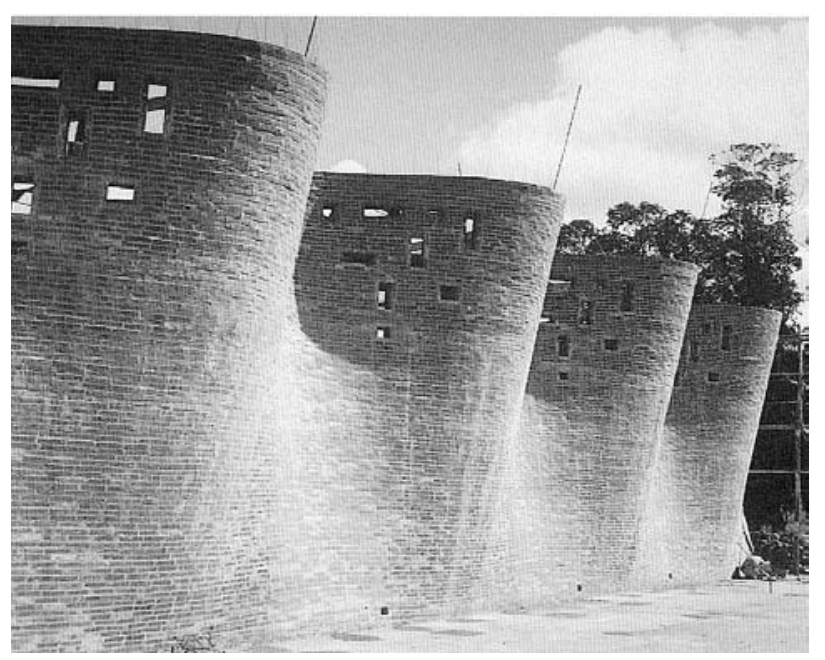

Figura 10.- Terminación de las paredes onduladas con las barras en espera para los tirantes de la cubierta.

zontal donde la serpenteante cornisa remata los muros. La cubierta varía su grado de ondulación, adquiriendo su máximo en el eje central de la Iglesia (Fig. 11).

Los empujes de la cubierta sobre la serpenteante cornisa, son contrarrestados por los tirantes que discurren por el canal de las ondulaciones de las Bóvedas Gausas (Fig. 2).

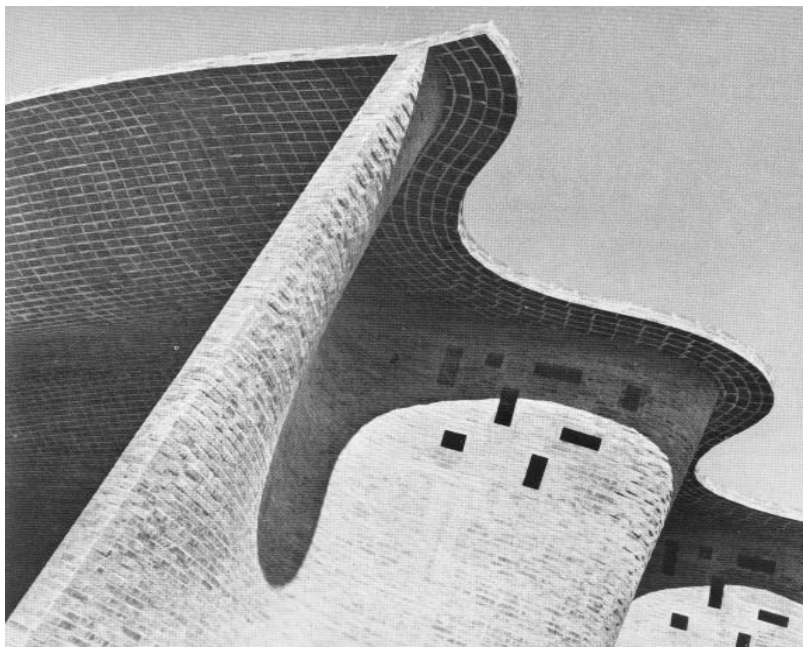

Figura 11.- Encuentro de la cubierta ondulada sobre el voladizo serpenteante de remate del muro.

Todo ello se hace posible al disponerse el ladrillo en retícula sobre los encofrados corridos ondulados y deslizantes de las cubiertas, interponiendo un armado mínimo de alambres en las dos direcciones de la ondulación de la cubierta, que quedan embebidos en el mortero que rellena las llagas de la retícula, además de las barras de los tirantes antes descritos (Fig. 12).

El resultado de la fábrica vista, muestra en las paredes onduladas el ladrillo a soga, mientras que en la ondulación de la cubierta, quedan a la vista las tablas de las piezas.

\section{- La Iglesia de San Pedro en Durazno (Uruguay, 1971)}

En la Iglesia de San Pedro Durazno (y en su réplica en la de Mejorada del Campo, 1998), Eladio Dieste plantea grandes tableros cerámicos postensados, generando grandes paños de planos rectos e inclinados, que parecen suspenderse en el espacio (Fig. 13).

En esta obra Dieste incorpora una tecnología mixta entre cerámica armada y hormigón armado, adquiriendo este último preponderancia con el postensado de los paños de fábrica, donde el ladrillo pasa a constituirse en un encofrado visto colaborante (Fig. 14).

Los grandes planos de la cubierta de Dieste en estas iglesias, descansan en ambos extremos de la nave, en el pórtico de acceso y en la torre del altar de forma poliédrica, constituyéndose en vigas pared de gran longitud y canto (Fig. 15).

El ingenio estructural genera una gran sorpresa, ya que se crea la sensación de que los muros se sostienen en el espacio por sí mismos, al no existir ningún soporte entre la nave central y las laterales de la Iglesia (Fig. 16). 


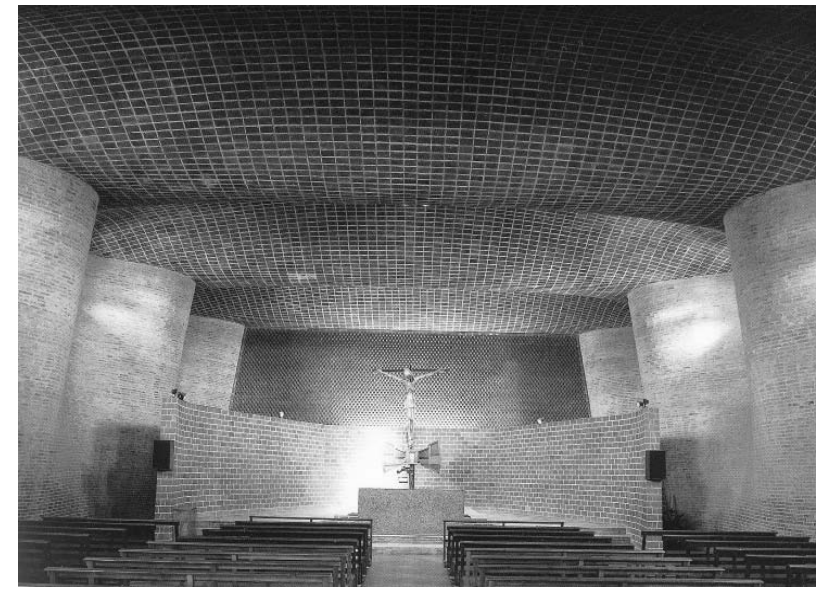

Figura 12.- Vista del interior de la Iglesia de la Atlántida, con paredes y cubiertas onduladas, mostrándose los ladrillos a soga en las paredes $y$ de plano en la cubierta.

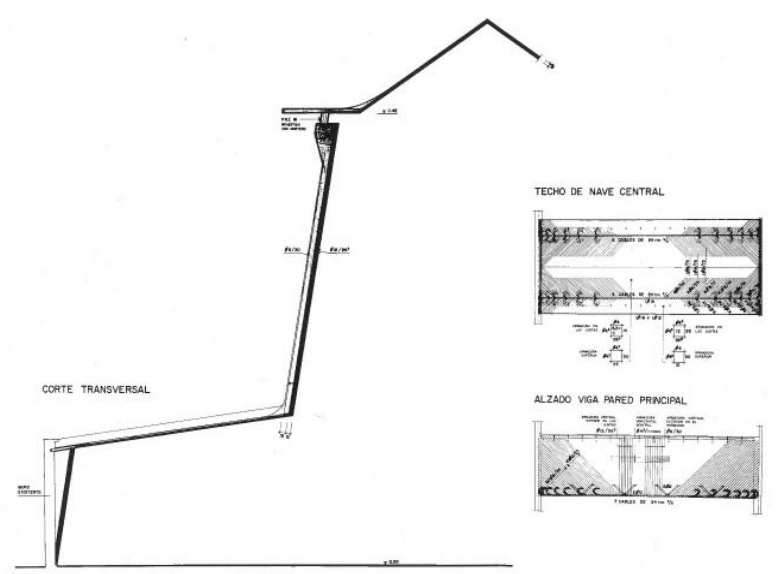

Figura 14.- Sección y detalles del armado de la viga pared de las naves laterales.

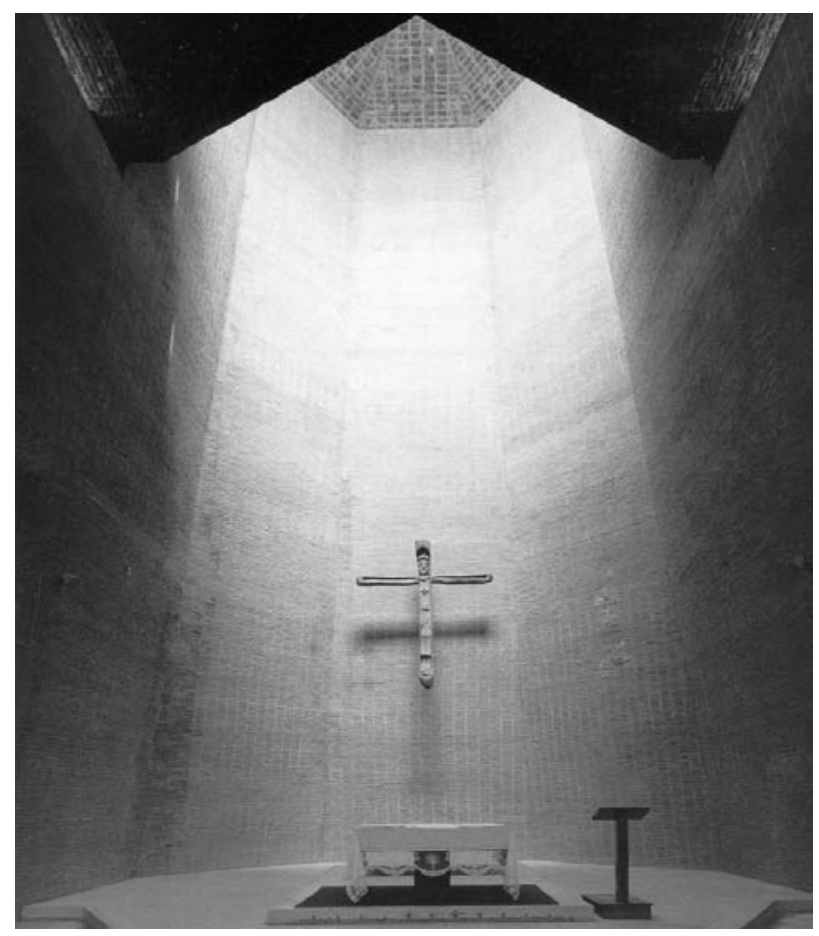

Figura 15.- Detalle de la viga pared en su encuentro con el altar poliédrico de la Iglesia de Mejorada del Campo.
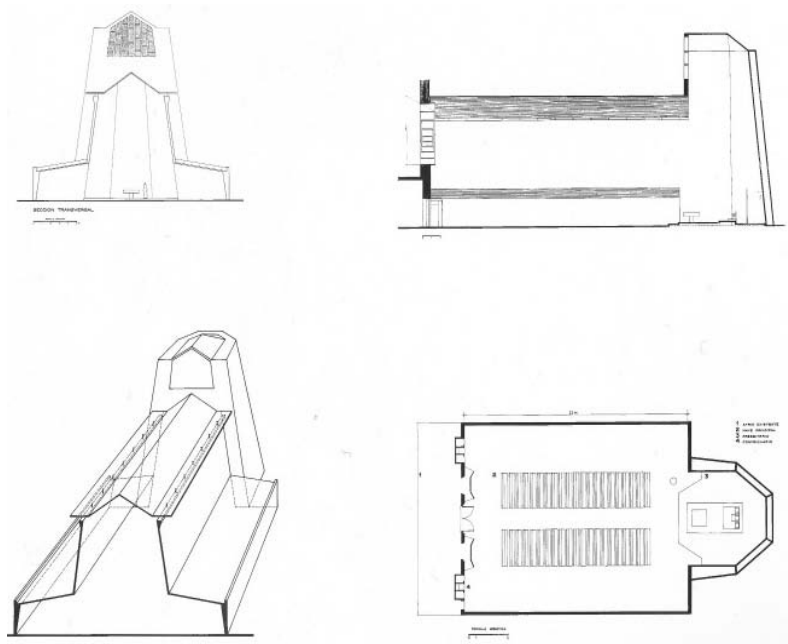

Figura 13.- Planta y secciones de la Iglesia de Durazno.

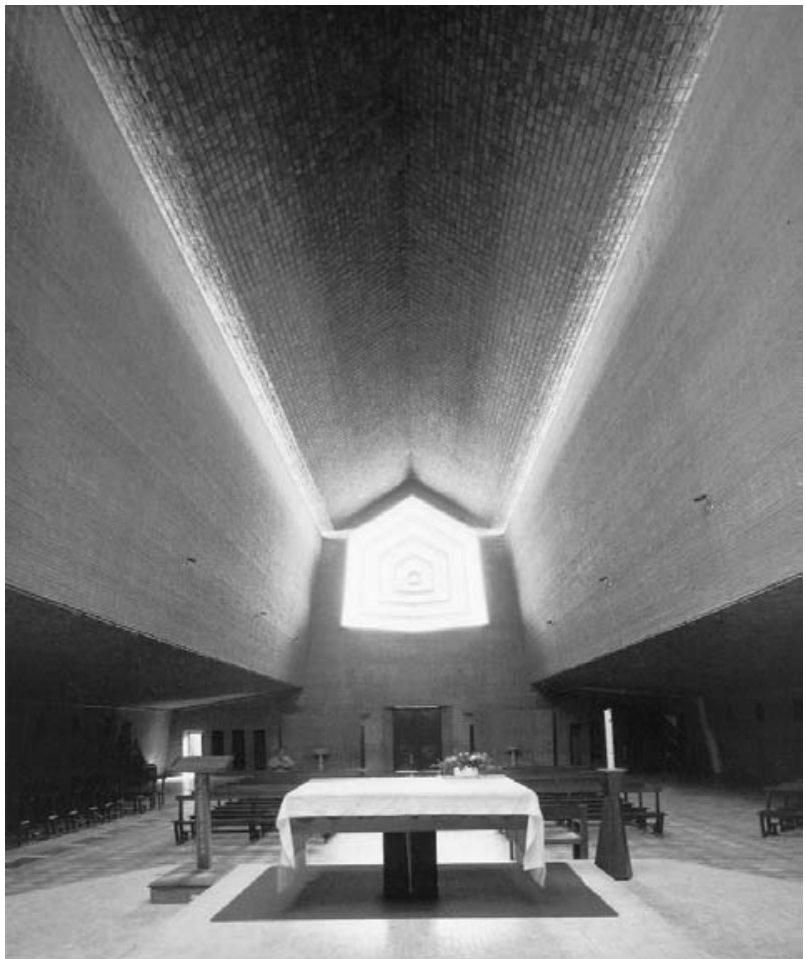

Figura 16.- Vista interior de la Iglesia de Durazno con el rosetón al fondo y la luz deslizándose entre la cubierta y las paredes.

Como podrá apreciarse en las imágenes, nuevamente el ladrillo se dispone sin aparejar, si bien en esta obra en las paredes inclinadas, el ladrillo manifiesta su soga en la retícula, mientras que en los planos inclinados de cubierta, muestra su tabla (ver portada).

Mención especial requiere la ingeniosa construcción del rosetón sobre el acceso de la iglesia (Fig. 17) (Fig. 18). Se trata de una figura de 5 anillos de tableros poligonales, hechos con el mínimo grueso del ladrillo $(4 \mathrm{~cm})$, que se 


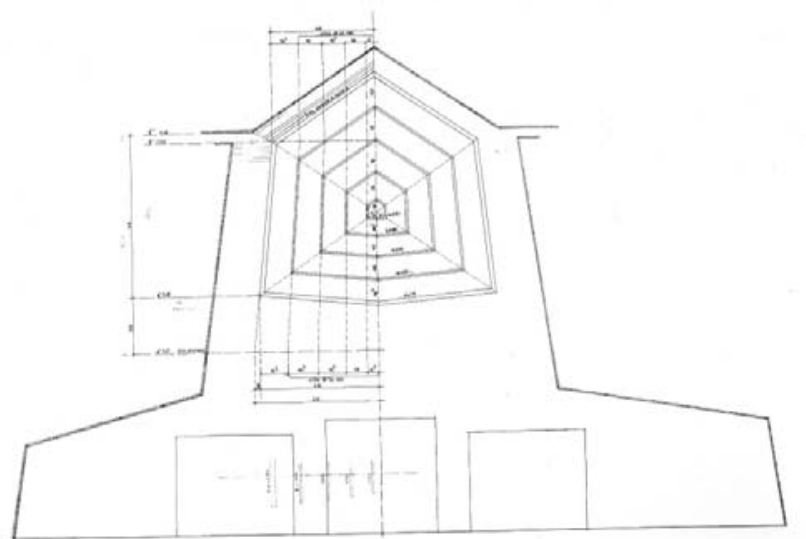

Figura 17.- Alzado de la organización del rosetón en los pies de la Iglesia de Mejorada del Campo.

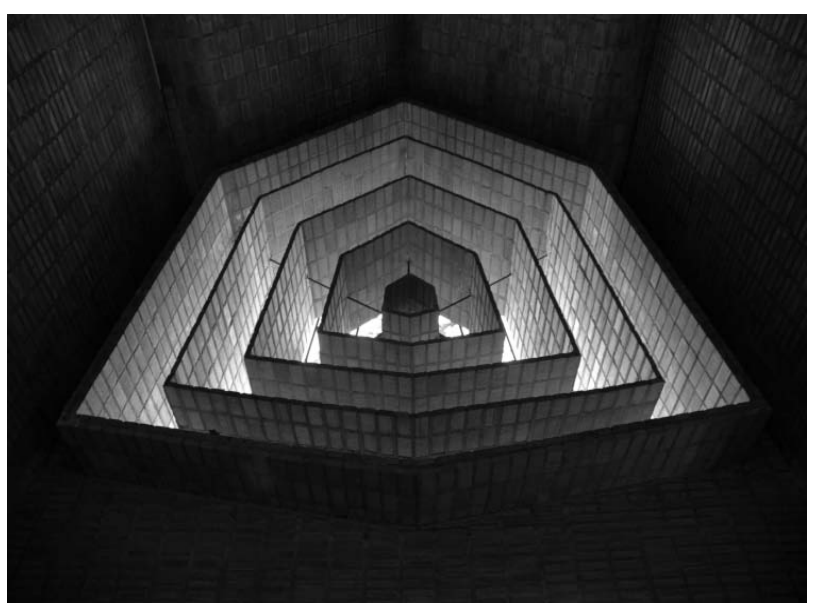

Figura 18.- Vista del rosetón con 5 tableros poligonales de $4 \mathrm{~cm}$ de grueso bidireccionalmente armados y postensados con redondos diagonales al fuego.

encuentran y afianzan entre sí en ángulo, gracias a la disposición de barras diagonales postensadas, cuyo postensado se hizo calentándolas al fuego para que se alargaran, y se posteriormente se acortaran al enfriarse, una vez ya fraguados los planos concéntricos de cerámica en retícula, con sus mallas de acero incorporadas entre las juntas.

La Iglesia del Rosario en Mejorada del Campo (Madrid) incorpora unas dependencias eclesiales junto al acceso donde pueden verse, junto a la fábrica sin aparejar, arcos de ladrillo que si no fuera por su armado interior reticular, no resistirían (Fig. 19, a y b).

\section{LA ARQUITECTURA SOSTENIBLE DE DIESTE}

Dieste ha sido muy crítico con la forma de plantearse la realidad de la Arquitectura, distinguiendo entre: "lo aparentemente práctico" y "lo hondamente práctico", plan-

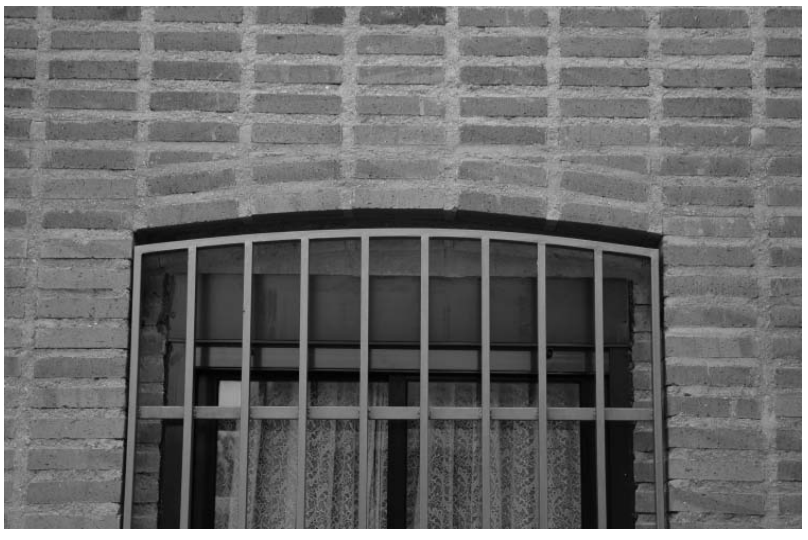

a)

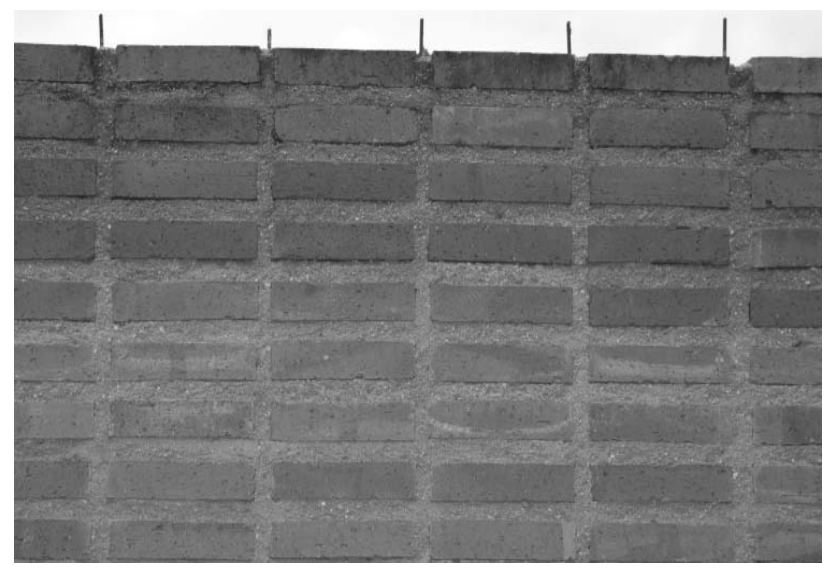

b)

Figura 19.- a) Detalle de la construcción reticular (y armada) de las dependencias de la Iglesia del Rosario en Mejorada del Campo (Madrid); b) Muro de fábrica sin aparejar con armado en retícula.

teando lo que él llama "la economía cósmica", que nada tiene que ver con el sentido financiero, ya que este último lleva muchas veces al despilfarro de la materia, buscando sólo el beneficio de lo inmediato.

Las obras de Eladio Dieste, hechas con cerámica estructural, han sido, en su mayoría, adjudicadas compitiendo económicamente con otras soluciones "más modernas" a las que la tecnología ideada por Dieste, ha ganado ampliamente por su menor coste de ejecución.

En todas sus edificaciones, el componente de mano de obra ha sido muy significativo, pero Dieste siempre ha sostenido que su influencia en el coste total no es tan significativa hasta el punto de seguir siendo sus soluciones económicamente competitivas, incluso en sociedades más desarrolladas. No en vano ha cubierto más de $1.000 .000 \mathrm{~m}^{2}$.

Podría decirse, pues, que Dieste se constituye con su obra arquitectónica, en un pionero de la sostenibilidad, pues se 
adelanta muchos años a los conceptos actuales de la sociedad, que propugna el empleo de los materiales obtenidos de la naturaleza de forma adecuada y sin despilfarrarlos, pudiendo llegar incluso a reutilizarse en etapas posteriores.

Eladio Dieste es un ingeniero trascendente que usa la luz en su lenguaje arquitectónico.

Las formas de sus obras obedecen a cuidadosas decisiones meditadas, surgidas de una técnica de lo imprescindible. Durante 40 años ha desarrollado diversos tipos en ladrillo: Tanques de agua; Torres; Edificios Industriales; Depósitos; Silos; Iglesias, etc.

Dieste significa un paso en el racionalismo del 27 que él utiliza de otro modo en su país.

No puede leerse ni entenderse la obra de Dieste sino se entra en el proceso y método constructivo, ya que todo lo de su obra siempre responde a algo.

Hasta la revolución industrial, la historia de la Arquitectura es la historia de la construcción con materiales frágiles (a excepción de la madera).

A partir de Dieste vuelven las bóvedas, pero con tracciones controladas (Guastavino, Candela, Dieste) con mucha más habilidad e inteligencia que lo hecho por sus antepasados, por la sabia disposición constructiva del acero en albañilería.

Así como Le Corbusier con una técnica nueva (el hormigón armado) revolucionó las formas de la Arquitectura, barriendo con el dintel al arco, Dieste, por el contrario, también con una nueva técnica (la cerámica estructural), retoma, sin embargo, el arco como la forma más económica de la construcción, en busca de una "economía cósmica" en la edificación.

\section{BIBLIOGRAFÍA}

Gaudi. Sert/Sweeney. Ed. Infinito. Alemania, 1960.

Eladio Dieste: La estructura cerámica. Facultad de Arquitectura Universidad de los Andes. Colombia. Colección SomoSur. Bogotá, Colombia, 1987.

Eladio Dieste revolution im Ziegelbau. Karl Ludwig Diehl.Revista Zieglindustrie Internacional. No 6/90. No 9/97. $9^{\mathrm{TH}}$ IBMAC. Berlín 1991.

La unidad recuperada. Eladio Dieste, formas y técnicas. Marina Waisman. Revista Arquitectura Viva, nº 18. Mayo-junio 1991.

Las bóvedas de la Atlántida. Adell. J.M. Revista Informes de la Construcción. Vol. 44. n ${ }^{\circ}$ 421. Instituto Eduardo Torroja. Consejo Superior de Investigaciones Científicas. Madrid, Septiembre/octubre, 1992 (págs. 113-123).

Eladio Dieste. 1943-1996. Consejería de Obras Públicas y Transportes. Dirección General de Arquitectura y Vivienda. Junta de Andalucía, 1996.

Artículos del libro:

"En la obra de Dieste...lo que no es indispensable no tiene cabida". A. Jiménez Torrecillas.

"Desde el sur". Alberto Petrina.

"Eladio Dieste, en el eje de la Historia". Marina Waisman.

"La cerámica armada". Eladio Dieste.

"Bóvedas Gausas". Eladio Dieste.

"Bóvedas Autoportantes". Eladio Dieste.

"Paredes de superficies regladas y láminas plegadas". Eladio Dieste.

"Tanques de agua y Torres". Eladio Dieste.

"Escritos del autor". Eladio Dieste.

- Conceptos

- Arquitectura y construcción

- La invención inevitable

- Técnica y subdesarrollo

- La conciencia de la forma

- Arte, pueblo, tecnocracia

- Conclusiones

Artículo "Muere el ingeniero Eladio Dieste, creador de bóvedas de ladrillo". Carlos Clemente. Diario El País. Madrid, 21 de julio de 2000. 